\title{
Pass Rates on the American Board of Family Medicine Certification Exam by Residency Location and Size
}

\author{
John L. Falcone, MD, MS, and Donald B. Middleton, MD
}

Background: The Accreditation Council for Graduate Medical Education (ACGME) sets residency performance standards for the American Board of Family Medicine Certification Examination. This study aims are to describe the compliance of residency programs with ACGME standards and to determine whether residency pass rates depend on program size and location.

Methods: In this retrospective cohort study, residency performance from 2007 to 2011 was compared with the ACGME performance standards. Simple linear regression was performed to see whether program pass rates were dependent on program size. Regional differences in performance were compared with $\chi^{2}$ tests, using an $\alpha$ level of 0.05 .

Results: Of 429 total residency programs, there were 205 (47.8\%) that violate ACGME performance standards. Linear regression showed that program pass rates were positively correlated and dependent on program size $(P<.001)$. The median pass rate per state was $86.4 \%$ (interquartile range, $82.0-$ 90.8. $\chi^{2}$ Tests showed that states in the West performed higher than the other 3 US Census Bureau Regions (all $P<.001)$.

Conclusions: Approximately half of the family medicine training programs do not meet the ACGME examination performance standards. Pass rates are associated with residency program size, and regional variation occurs. These findings have the potential to affect ACGME policy and residency program application patterns. (J Am Board Fam Med 2013;26:453-459.)

Keywords: Certification, Education, Educational Measurement, Family Practice, Geographic Factors, Residency, Specialty Boards

One of the criteria to meet initial certification requirements by the American Board of Family Medicine $(A B F M)$ is satisfactory performance on the ABFM Certification Examination (CE). This examination is a multiple choice, computer-based test that evaluates the cognitive domain and problemsolving ability relevant to family medicine. ${ }^{1}$ In 2006, the ABFM made a notable shift in the con-

This article was externally peer reviewed.

Submitted 19 November 2012; revised 27 February 2013; accepted 1 March 2013.

From the Departments of Surgery (J.L.F.) and Family Medicine (DBM), University of Pittsburgh School of Medicine, University of Pittsburgh Medical Center, Pittsburgh, PA.

Funding: none.

Conflict of interest: none declared.

Corresponding author: John L. Falcone, MD, MS University of Pittsburgh Medical Center, Presbyterian University Hospital, F-675, 200 Lothrop Street, Pittsburgh, PA 15213 (E-mail: falconej@upmc.edu). tent blueprint for the CE. This change directed relevant field content while focusing on the knowledge required to practice high-quality family medicine. In addition, the examination changed from the classic test theory psychometric model to one that relies on item response theory. ${ }^{2}$ Through item analysis, a recent study confirmed that the ABFM $\mathrm{CE}$ test questions were well written, provided minimal cueing, and required specific medical knowledge as opposed to a generalized test-taking ability to answer questions correctly. ${ }^{3}$ To improve performance on the examination, applicants are encouraged to increase their fund of medical knowledge and decision-making ability in clinical scenarios. ${ }^{4}$

The Accreditation Council for Graduate Medical Education (ACGME) sets standards for program performance on the ABFM CE. Poor performance is noted for residency training programs if the program's composite score is consistently at or 
below the 25 th percentile and/or $>10 \%$ of firstattempt examinees fail over a period of 3 to 5 consecutive years. ${ }^{5}$ On its public domain website, the ABFM publishes the performance of first-time examinees on the ABFM CE by individual residency program. ${ }^{6}$

On an individual level, the annual ABFM InTraining Examination has been shown to have adequate predictive validity regarding trainee performance on the ABFM CE. ${ }^{7}$ A similar correlation of performance has been found for the Certifying Board Examination and performance of the InTraining Examination in internal medicine. ${ }^{8}$ Moreover, medical school training may play a role in performance on the ABFM CE. One study showed that residents educated allopathically performed significantly better than their osteopathic counterparts when mean scaled scores were compared. This difference was not seen for graduates from dually accredited residency programs. ${ }^{9}$

The literature regarding residency program characteristics that are associated with improved performance on the ABFM CE is sparse. One regional study showed no statistical difference in performance between university-based and communitybased family medicine residency programs. ${ }^{10}$ In pediatrics and surgery, evidence suggests that larger programs outperform smaller programs. In addition, there are regional differences in performance, with the Northeast and Southern United States having poorer performance than other regions. ${ }^{11-13}$ In internal medicine, the number of residents per program who take the written certifying examination is positively correlated with the composite examination scores, indicating that program size is a predictor of performance. Furthermore, program characteristics have an effect on the cognitive skills of residents over and above what would be predicted by test scores at the end of medical school. ${ }^{14}$

The aims of this study are 3 -fold. The first is to evaluate the family medicine residency training programs in the United States and Puerto Rico with regards to the 2 ACGME performance standards. The second aim is to determine whether residency program size is associated with program pass rates over time. With larger residency programs having more resources for curricula and educational programs, and with similar findings in other specialties, we hypothesize that larger residency programs will have higher pass rates on the
ABFM CE. The third aim of this study is to describe variations in performance based on geography. On the basis of other specialties, we hypothesize that the Northeast and Southern United States will have lower pass rates on the ABFM CE than other regions.

\section{Methods}

In this retrospective cohort study from 2007 to 2011, the publicly available electronic data for residency program performance on the ABFM CE for all training programs in the United States and Puerto Rico were obtained from the ABFM website. ${ }^{6}$ The permission to cite and use published electronic data for research purposes was confirmed by the ABFM (Thomas O'Neill, Vice President of Psychometric Services for the ABFM, personal communication).

Programs were included if at least one resident had attempted the ABFM CE for 5 consecutive years, from 2007 to 2011. The program-specific numbers of first-time examinees and the examinees who passed the ABFM CE on the first attempt were extrapolated from the data set. The number of graduates per program also was obtained as an indicator of residency program size. Independent double data entry was performed to confirm the accuracy of the extrapolated data. Program performance then was compared with the 2 ACGME examination performance standards. For the 25 th percentile standard, overall 5 -year program performance was used. For the $10 \%$ program fail rate standard, fail rates were evaluated over 3-year (2009-2011), 4-year (2008-2011), and 5-year (2007-2011) intervals. Programs did not meet this ACGME standard criterion if the fail rate was $>10 \%$ during all time intervals.

A scatter plot showing residency program percent pass rates and the total number of graduates from 2007 to 2011 was created. To show whether family medicine residency program pass rates were dependent on residency program size, simple linear regression was performed using the 5 -year program pass rate on the ABFM CE as the dependent variable and the total number of graduating residents from 2007 to 2011 as the independent variable. One-tailed statistics were used. A Pearson correlation coefficient was found for these continuous variables.

To show regional differences in examination performance, state-wide pass rates were deter- 
Figure 1. Scatter plot of residency program pass rates on the American Board of Family Medicine Certification Examination and residency program size from 2007 to 2011 for 429 residency programs in the United States and Puerto Rico.

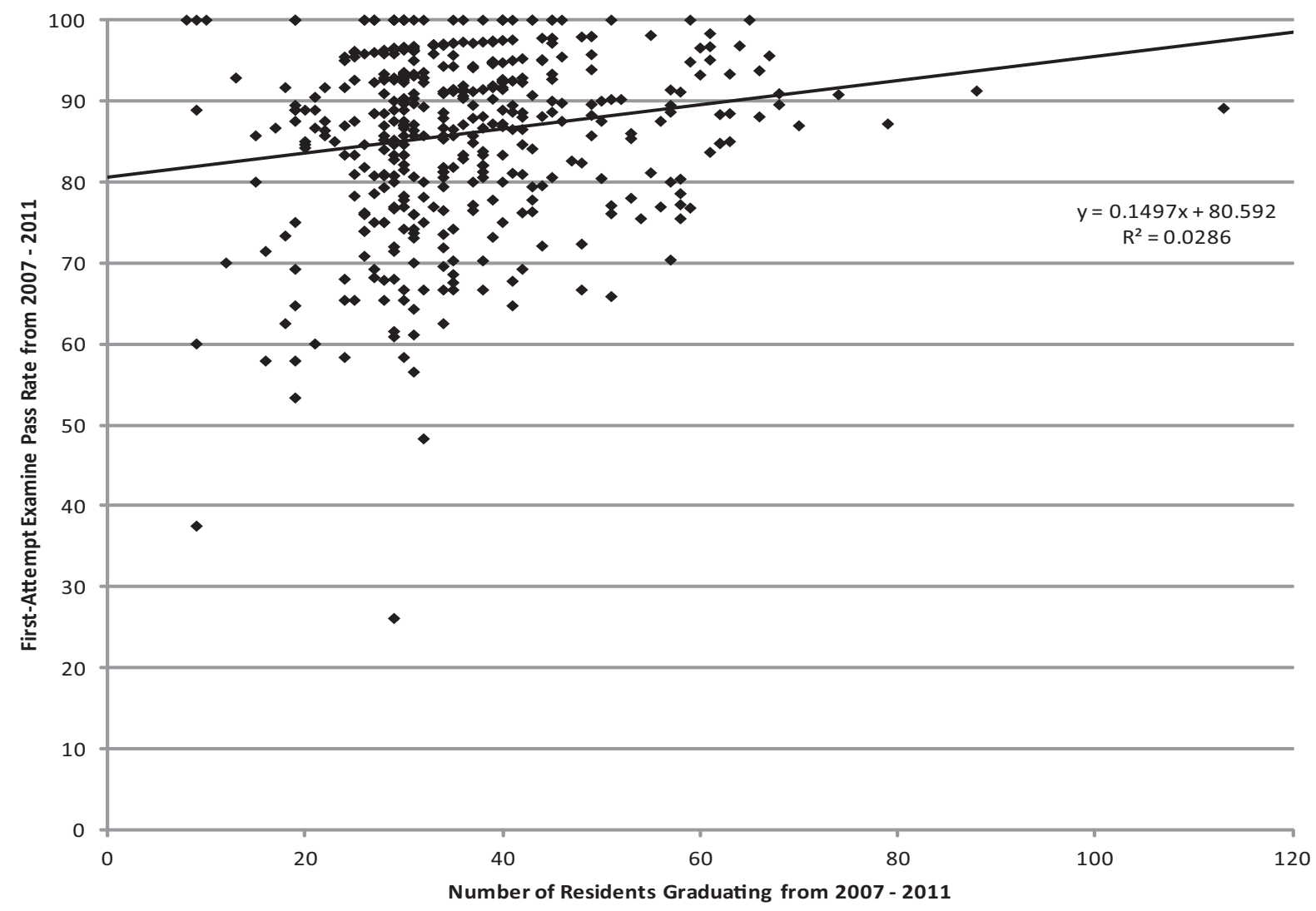

mined and mapped. Examinee performance also was determined for the 4 regions of the United States as recognized by the U.S. Census Bureau: Northeast, Midwest, South, and West. ${ }^{15}$ Differences in first-time examinees who passed and failed the ABFM CE were compared between U.S. Census Bureau regions using $\chi^{2}$ tests. All statistics were performed using Stata 11.1 statistical software (StataCorp, College Station, TX), using an $\alpha=$ 0.05 .

\section{Results}

Of the 478 family medicine residency programs in the United States and Puerto Rico, 429 residency programs $(89.7 \%)$ satisfied the inclusion criteria for this study. A total of 49 residency programs $(11.4 \%)$ did not have complete 5 -year data. The overall first-time examinee pass rate on the ABFM CE was $86.9 \%$ (12,507 of 14,394$)$.

The median number of graduates per residency program over the study period was 34 (interquartile range [IQR], 29-41). The median number of firsttime examinees per program was 31 (IQR, 26-39). The median residency program pass rate was $88.2 \%$ (IQR, $80.0 \%$ to $94.3 \%$ ). Regarding the 2 ACGME performance standards, 107 of 429 residency programs were at or below the 25 th percentile over the study period. There were 207 of 429 residency programs $(48.3 \%)$ that had a $>10 \%$ firsttime examinee fail rate over 3 years, 221 (51.6\%) over 4 years, and 244 (56.9\%) over 5 years. Overall, there were 205 residency programs (47.8\%) with $>10 \%$ first-time examinee fail rates over all time intervals.

The simple linear regression analysis using the total number of graduating residents per program as a predictor of ABFM CE pass rate from 2007 to 2011 is shown in Figure 1. The slope of the best-fit line was 0.15 (95\% confidence interval, 0.07-0.23); this slope was greater than zero $(P<.001)$. The Pearson correlation coefficient between these 2 variables was $0.17(P<.001)$. 
Table 1. Performance of First-Time Examinees on the American Board of Family Medicine Certification Examination from 2007 to 2011 in the United States and Puerto Rico

\begin{tabular}{|c|c|c|c|}
\hline State or Region & $\begin{array}{c}\text { Total } \\
\text { Examinees (n) }\end{array}$ & $\begin{array}{c}\text { Passing } \\
\text { Examinees (n) }\end{array}$ & $\begin{array}{c}\text { Pass } \\
\text { Rate (\%) }\end{array}$ \\
\hline Montana & 30 & 29 & 96.7 \\
\hline Idaho & 77 & 74 & 96.1 \\
\hline Utah & 119 & 113 & 95.0 \\
\hline Washington & 412 & 390 & 94.7 \\
\hline Missouri & 242 & 227 & 93.8 \\
\hline Minnesota & 361 & 338 & 93.6 \\
\hline Oregon & 130 & 121 & 93.1 \\
\hline Colorado & 295 & 273 & 92.5 \\
\hline California & 1502 & 1385 & 92.2 \\
\hline South Dakota & 63 & 58 & 92.1 \\
\hline Maine & 110 & 101 & 91.8 \\
\hline South Carolina & 303 & 276 & 91.1 \\
\hline Pennsylvania & 857 & 779 & 90.9 \\
\hline Indiana & 357 & 324 & 90.8 \\
\hline Vermont & 31 & 28 & 90.3 \\
\hline North Carolina & 442 & 399 & 90.3 \\
\hline Florida & 510 & 456 & 89.4 \\
\hline Michigan & 561 & 498 & 88.8 \\
\hline Rhode Island & 60 & 53 & 88.3 \\
\hline Iowa & 268 & 236 & 88.1 \\
\hline Kentucky & 146 & 128 & 87.7 \\
\hline Virginia & 372 & 326 & 87.6 \\
\hline Kansas & 183 & 160 & 87.4 \\
\hline Oklahoma & 214 & 186 & 86.9 \\
\hline Massachusetts & 183 & 159 & 86.9 \\
\hline Nebraska & 187 & 162 & 86.6 \\
\hline Wisconsin & 312 & 269 & 86.2 \\
\hline Texas & 1086 & 933 & 85.9 \\
\hline Maryland & 77 & 66 & 85.7 \\
\hline Nevada & 42 & 36 & 85.7 \\
\hline Hawaii & 62 & 53 & 85.5 \\
\hline Ohio & 596 & 506 & 84.9 \\
\hline Illinois & 810 & 681 & 84.1 \\
\hline North Dakota & 68 & 57 & 83.8 \\
\hline West Virginia & 147 & 123 & 83.7 \\
\hline Delaware & 54 & 45 & 83.3 \\
\hline New Jersey & 341 & 283 & 83.0 \\
\hline Arizona & 184 & 152 & 82.6 \\
\hline Alabama & 196 & 161 & 82.1 \\
\hline Arkansas & 221 & 180 & 81.4 \\
\hline Tennessee & 242 & 193 & 79.8 \\
\hline Washington, DC & 62 & 49 & 79.0 \\
\hline Georgia & 329 & 260 & 79.0 \\
\hline New York & 837 & 661 & 79.0 \\
\hline Mississippi & 71 & 56 & 78.9 \\
\hline \multirow[t]{2}{*}{ Alaska } & 50 & 39 & 78.0 \\
\hline & & & Continued \\
\hline
\end{tabular}

Table 1. Continued

\begin{tabular}{lccc}
\hline State or Region & $\begin{array}{c}\text { Total } \\
\text { Examinees (n) }\end{array}$ & $\begin{array}{c}\text { Passing } \\
\text { Examinees (n) }\end{array}$ & $\begin{array}{c}\text { Pass } \\
\text { Rate (\%) }\end{array}$ \\
\hline Louisiana & 229 & 177 & 77.3 \\
New Hampshire & 42 & 32 & 76.2 \\
New Mexico & 104 & 79 & 76.0 \\
Wyoming & 52 & 36 & 69.2 \\
Connecticut & 86 & 58 & 67.4 \\
Puerto Rico & 79 & 43 & 54.4 \\
\hline
\end{tabular}

The state-wide and regional pass rates on the ABFM CE are given in Table 1. The median number of resident examinees per state during the study period was 185.5 (IQR, 75.5-345). The median pass rate per state or region was $86.4 \%$ (IQR, $82.0 \%$ to $90.8 \%)$. A coded map of the continental United States showing ranked state-wide differences in performance is given in Figure 2.

First-time examinee performance by to the US Census Bureau regions is given Table 2. $\chi^{2}$ Tests showed that states in the West performed higher than the other 3 regions (all $P<.001$ ). Seven of the 9 highest-performing states were located in the West. $\chi^{2}$ Tests showed that the Northeast and the South performed lower than both the Midwest and the West (all $P \leq .001$ ) but revealed no differences in performance between the Northeast and the South $(P=.35)$.

\section{Discussion}

In this retrospective study, by definition, we have shown that there are 107 of 429 family medicine residency programs that were at or below the 25 th percentile from 2007 to 2011. Even more worrisome is that there are 205 family medicine residency programs $(47.8 \%)$ that have failed to maintain a $\leq 10 \%$ fail rate over 3 - to 5 -year time intervals for first-time examinees on the ABFM CE. Approximately half of the residency programs are at risk of being cited for failure to meet published ACGME guidelines.

Interestingly, there were more residency programs that had a $\leq 10 \%$ fail rate in the past 3 years as opposed to the last 4 and 5 years. This is an indication that residency programs have improved their outcomes no recent examination. Notable improvements in examination performance is one of the considerations of the ACGME. ${ }^{5}$ Residency program citation for board performance is com- 
Figure 2. Map of the performance of first-time examinees on the American Board of Family Medicine Certification Examination from 2007 to 2011 in the continental United States.

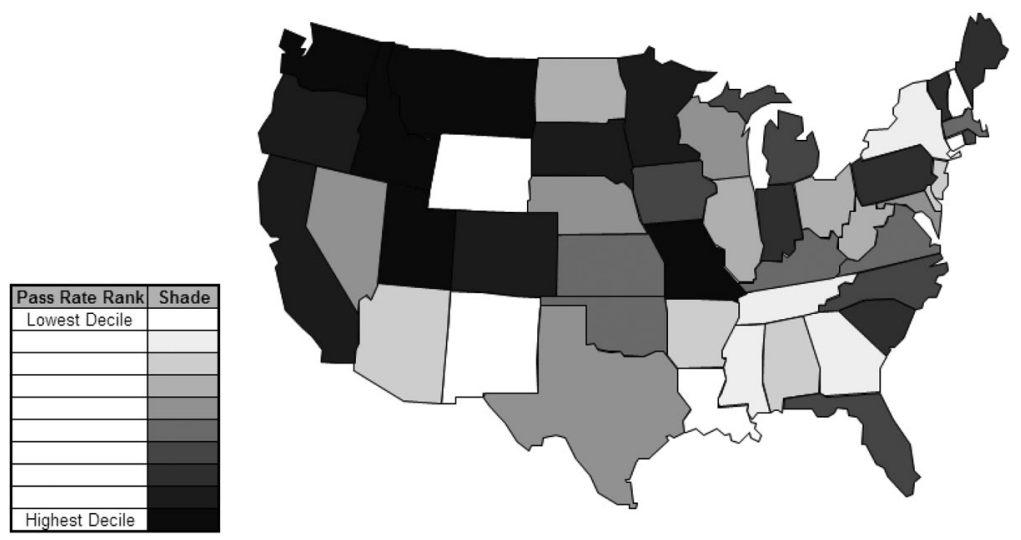

mon. In 2009, 32 of 114 programs (28.1\%) were cited with regard to board scores; this was the second-most common citation. ${ }^{16}$ The potential citation rate of $47.8 \%$ found in this study is higher than the $28.1 \%$ actual recent citation rate. First, this study evaluates all programs, whereas individual programmatic review does not occur annually. Second, the definition of "notable improvement" is not evaluated in this study. Finally, these data suggest that overall program performance has improved the most since 2009. Notably, all these program improvements occurred after the change to the examination blueprint in $2006,{ }^{2}$ suggesting that changes are not due to the examination itself, but to changes in the examinees or programmatic variables.

Regardless, the high proportion of residency programs that fail to meet the $90 \%$ pass rate standard makes us wonder whether the $90 \%$ pass rate standard for family medicine should be changed. In internal medicine and pediatrics, for

Table 2. Performance of First-Time Examinees on the American Board of Family Medicine Certification Examination from 2007 to 2011 for the Four United States Census Bureau Regions

\begin{tabular}{lcccc}
\hline Region & $\begin{array}{c}\text { Passing } \\
\text { Examinees } \\
(\mathrm{n})\end{array}$ & $\begin{array}{c}\text { Failing } \\
\text { Examinees } \\
(\mathrm{n})\end{array}$ & $\begin{array}{c}\text { Total } \\
\text { Examinees } \\
(\mathrm{n})\end{array}$ & $\begin{array}{c}\text { Pass } \\
\text { Rate } \\
(\%)\end{array}$ \\
\hline Northeast & 2154 & 393 & 2547 & 84.6 \\
Midwest & 3516 & 492 & 4008 & 87.7 \\
South & 4014 & 687 & 4701 & 85.4 \\
West & 2780 & 279 & 3059 & 90.9 \\
Total & 12,464 & 1851 & 14,315 & 87.1 \\
\hline
\end{tabular}

example, the ACGME pass rate standards for first-time examinees are $80 \%$ and $60 \%$, respectively. ${ }^{5}$ Given that the overall pass rate for firsttime family medicine examinees during the study period was $86.9 \%$, we feel that the $90 \%$ pass-rate policy standard should be reevaluated. The only other discipline that has an ACGME program percentile requirement is in radiation oncology (25 th percentile). ${ }^{5}$

We also have demonstrated that program size is associated with 5 -year pass rates on the ABFM CE; the findings shown through linear regression are consistent with our hypothesis. These results are similar to results shown in pediatrics and surgery. ${ }^{11,12}$ However, the magnitude of the Pearson correlation coefficient is very small and is evident in the wide variability shown in Figure 1. It is unlikely that size alone is associated with examinee performance. It is more likely that confounding variables associated with program size account for this difference in educational outcomes. The nature of curricula, the ability to attract specialized faculty, higher-quality residents, and established education programs could be a few potential reasons that larger programs outperform smaller programs in general. There are also individual variables that may be associated with program size, including individual variables such as allopathic or osteopathic training, age, duration of training, and time between residency and taking the ABFM CE. These potential programmatic and individual variables should be studied in the future to determine whether they have any predictive validity for examination performance. 
Finally, we have shown clear differences in regional performance on the ABFM CE, consistent with our study hypothesis. The Northeast and the South performed at lower levels than the Midwest and the West. Interestingly, some programs in the Northeast and South do have $100 \%$ pass rates for first-time examinees on the ABFM CE. Residency program performance is extremely complex and depends on multiple factors, such as resident selection, curriculum structure, faculty recruitment, and incentives.

Other areas of concern for our study include its retrospective cohort design. We are unable to establish any causation between variables. Second, there are multiple potentially confounding variables related to program size. We could not define exactly which variables are responsible for higher program performance. Importantly, we did not study the programs that have been cited for failing to meet the ACGME examination performance standards; this study was a retrospective analysis of programs that did not meet the published ACGME examination performance standards based on published performance on the ABFM CE. Finally, this study does not evaluate any patient-related outcomes or any clinical outcomes of examinee performance- only binary outcomes on the ABFM CE.

However, among the strengths to this study is that it evaluates the vast majority of family medicine training programs in the United States and Puerto Rico, reviewing the entire examinee population that attempts the ABFM CE as opposed to a smaller cohort of local or regional examinees. Since the data are publically available, this study is easily reproducible. This research also has longitudinal validity in that recent performance over 5 years is evaluated. This study is the first to evaluate the current state of family medicine residency program performance on the ABFM CE and its relation to the important ACGME program criteria and the demographic factors associated with higher performance on the ABFM CE.

The findings of this study have a few implications. First, it notes an alarming potential citation rate for residency training programs that are at risk. This finding might lead to a reevaluation of the ACGME program performance policy standards. This study may also shift the potential application and interview patterns toward residency programs in the West, larger residency programs, and programs that have a recent history of strong performance on the ABFM CE.

\section{References}

1. The American Board of Family Medicine. Maintenance of certification. Part III-cognitive expertise. Available from: https://www.theabfm.org/moc/part3. aspx. Accessed June 19, 2012.

2. Norris TE, Rovinelli RJ, Puffer JC, Rinaldo J, Price DW. From specialty-based to practice-based: a new blueprint for the American Board of Family Medicine cognitive examination. J Am Board Fam Pract 2005;18:546-54.

3. O’Neill TR, Royal KD, Puffer JC. Performance on the American Board of Family Medicine (ABFM) Certification Examination: are superior test-taking skills alone sufficient to pass? J Am Board Fam Med 2011;24:175-80.

4. Royal KD, Puffer JC. The reliability of American Board of Family Medicine examinations: implications for test takers. J Am Board Fam Med 2012;25:131-3.

5. Specialty-specific references for DIOs: board certification requirements and pass rate information. June 2011. The Accreditation Council for Graduate Medical Education (ACGME). Available from: http:// www.acgme.org/acgmeweb/Portals/0/DIO_Board_Pass_ Rate.pdf. Accessed January 17, 2013.

6. The American Board of Family Medicine. Residency Performance Online. Available from: https:// www.theabfm.org/Search.aspx? q=\%22American + Board + of + Family + Medicine + Residency + Program + Certification + Performance + Summary $\% 22$. Accessed January 17, 2013.

7. Replogle WH, Johnson WD. Assessing the predictive value of the American Board of Family Practice in-training examination. Fam Med 2004;36:185-8.

8. Rollins LK, Martindale JR, Edmond M, Manser T, Scheld WM. Predicting pass rates on the American Board of Internal Medicine certifying examination. J Gen Intern Med 1998;13:414-6.

9. Puffer J. The American Board of Family Medicine certification examination: a proxy for quality. Fam Med 2011;43:433-4.

10. Davidson RC, Kahn NB Jr. A comparison of university-based and community-based family practice residency programs. J Fam Pract 1984;18:581-6.

11. Falcone JL. Compliance on the American Board of Pediatrics certifying examination and the importance of location and size on pass rates. Clin Pediatr (Phila) 2012;51:483-9.

12. Falcone JL, Hamad GG. The state of performance on the American Board of Surgery Qualifying Examination and Certifying Examination and the effect of residency program size on program pass rates. Surgery 2012;151:639-42.

13. Falcone JL, Hamad GG. The American Board of Surgery Certifying Examination: a retrospective 
study of the decreasing pass rates and performance for first-time examinees. J Surg Educ 2012;69: 231-5.

14. Norcini JJ, Grosso LJ, Shea JA, Webster GD. The relationship between features of residency training and ABIM certifying examination performance. J Gen Intern Med 1987;2:330-6.

15. United States Census Bureau. Census regions and divisions of the United States. Available from: http:// www.census.gov/geo/www/us_regdiv.pdf. Accessed June 19, 2012.

16. Martin J, Meyer L. Updates from the Residency Review Committee for Family Medicine. The Accreditation Council for Graduate Medical Education (ACGME). Available from: http://www.acgme.org/ acgmeweb/Portals/0/PFAssets/Presentations/120_ Family_Medicine_Review_Cycle_of_Cores_and_subs. pdf. Accessed January 17, 2013. 